\title{
La teología de la liberación frente al cambio sociohistórico de América Latina
}

\author{
Ignacio Ellacuría \\ Centro de Reflexión Teológica. \\ San Salvador, El Salvador.
}

La teología de la liberación pretende un cambio no sólo en las personas y en la sociedad, sino también en las estructuras socio-históricas de América Latina y, por extensión, de otras partes del mundo, en cada caso según sus circunstancias. Ese cambio se nombra e interpreta en términos de liberación. Esa liberación que en términos teológicos puede expresarse paulatinamente como una liberación del pecado, de la ley y de la muerte, puede expresarse en términos históricos como liberación de todo aquello que oprime al hombre y le impide gozar de su vocación de hijo libre de Dios. Esta teologla parte de una experiencia fundante, que le acompafia en todo su desarrolo teórico, consistente en la comprobación física y en la vivencia de que la mayor parte de la población latinoamericana vive en condiciones de pobreza y/o miseria y de opresión social y política, resultado de una injusticia estructural histórica, de la cual son responsables por comisión u omisión distintos sujetos sociales (clases, naciones, imperios) y distintos dinamismos económicos y políticos. Ante esta situación la teologia de la liberación, primero como movimiento de fe más o menos reflexiva, y después como reflexión racional explícita, se pregunta qué dice la fe cristiana tanto en el orden de las causas como en el orden de las soluciones, y se pregunta asimismo qué debe hacerse desde esa fe para conseguir que los pueblos oprimidos consigan a través de procesos de liberación convertirse en pueblos libres, que como tales puedan realizar y gozar lo que es posible históricamente de la presencia del reino de Dios entre los hombres.

Esto se plantea de forma distinta si se subraya la liberación de la teologia (Segundo) o si se subraya la teología de la liberación (Gutiérrez). En el primer caso, lo que se pretende más inmediatamente es que la fe y la teologfa se liberen en lo que ellas mismas han tenido de contribución ideológica y social a que la religión y/o la fe cristiana hayan sido parte de la opresión, quedando así dispuestas a desempeñar su propia función de acompantar debidanente los procesos personales y sociales de liberación. En el segundo caso, lo que se pretende más inmediatamente es utilizar la fuerza social de la fe y de la Iglesia en la liberación socio-histórica de los pueblos. Lo que más importa de la teología de 
La liberación, se nos dice, es la liberación, pero en el primer caso el objetivo inmediato es la liberación de la teologia, mientras que en el segundo caso es la liberación de la injusticia estructural, lo cual obligara forzosamente a una liberación de la teologfa. Pero tanto en un caso como en el otro lo que se pretende es hacer una auténtica y total teologla y, antes, un auténtico y total proceso cristiano, que aberque todas las exigencias del reino de Dios.

Es importantes resaltar que aun en el segundo caso, y con mayor razón en el primero, la teologia de la liberación pretende ser, primero algo estrictamente teológico y, segundo, algo que pueda estimarse como una teología total. Lo primero significa que la teología de la liberación pretende situarse en la tradición teológica y pretende situarse en aquel modo de racionalidad que pretende ser la teologla, sin desconocer el hecho de que la teologia se ha entendido a si misma como saber desde distintas formas de racionalidad. No es, por tanto, la teología de la liberación una sociologia o una politología, sino un modo de saber específico, cuyas fuentes o principios son la revelación, la tradición y el magisterio, a cuyo servicio se ponen ciertas mediaciones. Si entre estas mediaciones tiene cierta imporuncia la de las ciencias socio-económicas-históricas-pollticas no implica necesariamente que se transforme en una de estas ciencias con lenguaje teológico, así como la preferencia clísica por la mediación de la filosofla no hacía necesariamente de la teologia anterior una forma de filosoffa. En la intención, en la metodología, en los hechos, la teologia de la libereción se muestra cada vez más como una teologia.

Lo segundo que ha de resaltarse en consonancia con lo primero es que la teologia de la liberación no es una teología regional, sino una teología total, no es una teologia de lo político, sino que es una teología del reino de Dios. Ciertamente tiene una clara vocación polftica, pues político es pretender la liberación no sólo de las personas, sino de los pueblos, no sólo de las opresiones psicológicas, sino también de las socio-históricas. Esta pretensión, necesita tenerse muy en cuenta, pues hace que, al menos en parte, la teologia sea una teologia política, pero no de til modo que de la teología sólo importe su significado y su eficacia políticos, ya que ella tiene su estricta consistencia teológica. Y esta consistencia hace que forzosamente tome como objeto (disúngase objeto tratado de objetivo pretendido) lo que se juzga ser el objeto de una teologia total. El entender este objeto como reino o reinado de Dios hace que, por un lado, no se deje fuera nada de lo que es el mensaje revelado y por otro, permite acercarse connaturalmente a las cosas de este mundo, porque en definitiva el reino de Dios, punto central del mensaje de Jesús, alude a la presencia reinante de Dios en esie mundo, al Dios que se hace historia para que la historia se alce hasta Dios, a la humanización y mundanización de Dios para que el hombre y el mundo se divinicen. Todo ello en la persuasión creyente de que el hombre sólo cuando sea más que hombre por la donación de Dios podrá llegar a ser hombre, según el pensamiento tradicional que en San Agustín tiene tan felices expresiones. Y lo mismo que vale del hombre, vale también del mundo y de la historia. 
Pero insistir en el carácter teológico total de la teología de la liberación no debe impedir su eficacia política, porque la fe y la teología tienen o deben tener una clara vocación liberadora del pecado en todas sus formas, no excluidas sus objetivaciones; de la ley en todos sus modos a través de los cuales el poder se impone sobre quien no lo tiene tanto dentro como fuera de lo religioso; de la muerte en todos aquellos procesos que van anulando la vida o aun arrebatándola antes de tiempo.

La teologia de la liberación, como forma plena de entender la fe cristiana y de llevarla a la práctica, no es, sin embargo, suficiente por sí misma para traer la liberación integral a las personas y a los pueblos. Por otra parte, se encuentra con otras fuerzas, que también se han percatado del estado de opresión en que viven las mayorias populares, que se han conmovido por ello y que, como fuerzas socio-historicas, se han propuesto desde su propia especificidad luchar por esta liberación. Esto plantea la cuestión de cúl debe ser la relación de la teología de la liberación, con esas otras fuerzas, sin las cuales no se puede obtener la liberación, que dice pretender como objetivo la primera para que efectivamente Dios reine en el mundo, para que Dios sea todo en todo. La cuestión surge sobre todo, tanto práctica como teóricamente, en relación con los llamados movimientos revolucionarios que han levantado la bandera de la liberación popular, pero también respecto de cualquier otro movimiento histórico que realmente pretenda el mismo objetivo. Hipotéticamente puede suponerse que la teología de la liberación no es suficiente de por si para levar a los pueblos una liberación efectiva y que los movimientos de liberación no son suficientes por sí para dar a los pueblos una liberación integral. Tal hipótesis arranca del presupuesto creyente de que sin Dios al como se nos da y revela en Jesús no hay salvación (liberación), pero es una hipótesis que, por otro lado, se apoya en la constatación de que la salvación de Jesís, lejos de separarse de los procesos históricos de liberación, los reclama en función de la unidad transcendental de la historia de la salvación. No hay dos historias, sino una sola historia en la cual se articulan la presencia del Dios liberador $y$ la presencia del hombre liberado y liberador. Las antiguas formulaciones de cómo aunar en lo interpretativo la fe y la razón y en lo realizable, la gracia y la naturaleza, se presentan de forma nueva en la teología de la liberación, la cual se pregunta cómo interpretar unitariamente el mundo desde la teología que es una fe en busca de entendimiento y cómo realizar históricamente el reino de Dios, que no deja fuera de si nada de lo que es, nada de lo que ha sido creado.

\section{Tipologia de algunas actitudes ante el desaffo político de la} teologia de la liberación

La teologfa de la liberación tiene que ver con lo político y esto hace que tenga que ver con la política. Tiene un claro proposito de liberación y de liberación efectiva, sobre todo en el modelo de teología de la liberación. Es este modelo el que presenta problemas más difficiles, pues el de la liberación de la teología, más 
que entrar en relación con procesos estrictamente políicos y revolucionarios, entra en relación con problemas de desideologización, que permiten cierta separación de la praxis política. Las dificultades surgen del tipo de actitud con la cual se enfrenta el problema, entendiendo por actitud la posición y disposición fundamental que se adoptan al querer hacer efectiva en la histora la teología de la liberación, la liberación que esa teología propone, que ha de aliarse de algún modo con aquellas fuerzas que también luchan por la liberación de las mayorías populares, por la liberación integral a partir de la liberación de los pobres.

El moralismo ingenuo no es una actitud usual entre quienes se mueven en el ámbito de la teologia de la liberación, pero en lo que puede tener de verdad se hace presente de una manera o de otra. El moralismo ingenuo, por un lado, supone que la fe cristiana se ha de centir al ámbito de la moral, tanto personal, como social y política, y además, que la fe cristiana en su propósito de liberación, no ha de mancharse las manos con las prácticas poco morales de la política o con los males más o menos necesarios de los movimientos políticos. Propende a convertirse en un moralismo abstractizante, general y universal, que huye el enfrentamiento con los hechos concretos con el pretexto de que éstos tienen siempre algo de política (mala o ambigua) y mucho más huye de apuntar hacia objetivos políticos determinados históricamente, pues ninguno de ellos se adecúa con las exigencias del reino. En su caso más extremo quiere reducir la función de la liberación estrictamente cristiana al cambio de los corazones y a la proclamación de ideales abstractos y busca no ser tildada de partidista, como si todas las fuerzas sociales y políticas fueran igualmente buenas o igualmente malas y no se pudiera desde la fe discernir cuál es la que más contribuye a la liberación iluminada con la luz del evangelio. Sefiala bien esta actitud las diferencias entre el modo de buscar la liberación por parte de la fe y por parte de la acción política, correspotdiente a la especificidad de la fe y de la acción políica, pero no consigue la debida articulación. Se trata de dos cosas distintas, dos cosas que tienen relación, pero esa relación se establece más en términos de paralelismo que de determinación mutua y, en algumos casos, de interacción.

El fanatismo fundamentalista y el simplismo mesiánico son actitudes que esperan toda la liberación sólo de la fe. Supone que hay una solución específicamente cristiana a los problemas políticos, económicos y sociales, aunque til vez no para los problemas tecnológicos. No son necesarias otras mediaciones téricas para descubrir las causas y proponer soluciones ni tampoco mediaciones prácticas para ponerlas en préctica Basta con vivir el cristianismo desnudamente para encontrar por connaturalidad lo que realmente liberara al pobre. No se trata de un espiritualismo sino que, al contrario, se trata de extender connaturalmente el mensaje liberador del evangelio a cuanto problema humano se presente. No hay problema real para el cual no se pueda encontrar solución desde la fe. Esto lleva con frecuencia a un radicalismo indiferenciado en las denuncias y a un idealismo utópico en las propuestas de solución. Se trata del evangelio sin glosa no sólo para la vida personal, sino para la vida social. Basa con la voluntad y el compromiso para terminar con la opresión. Para la negación, sobre todo, hay total 
facilidad, aunque siempre sea un poco más dificil delinear el contenido de la afumación. Todo lo que no sea el ideal evangélico de sentar a los pobres en el trono y de derrocar al poderoso de su sede son componendas, y no es aceptable. En el mejor de los casos basta con un mínimo de esquemas interpretativos y de organización para conseguir el poder y transfornar la realidad. La praxis liberadora irá dictando lo que se debe destruir y lo que se debe construir. Esta radicalidad, que es más bien radicalismo, leva fácilmente a medir la bondad o maldad, la eficacia o ineficacia, por el grado de radicalismo sin medir mucho las consecuencias ni calcular los tiempos. Hay una fe ciega en la bondad de la propia actitud y posición y una seguridad mesiánica del triunfo. Lo importante es que no se apague el fuego, que no se extinga la esperanza ni la pasión. El retraso en el triunfo o los cadáveres que quedan en el camino no importan. Dios acabará triunfando con su pueblo. Aquí también puede gritarse "revolución o muerte," el lodo o la nada. Seffala bien esta actitud la fuerza de la fe y su historicidad, su capacidad de hacer historia por sí misma y de realizar de algún modo la liberación, pero no atiende a la terquedad y opacidad de la realidad opresora, a la posible lentitud de los tiempos históricos, a la totalidad de la complejidad histórica, que no puede ser denominada ni teórica ni prácticamente por los contenidos de la fe, ni siquiera por la luz de la fe en busca de nuevos contenidos.

El reduccionismo toma una doble forma Por un lado, se interesa solo por aquellos aspectos de la fe cristiana, que tienen inmediata relevancia política, dejando en penumbra o en suspenso otros aspectos y aun la dimensión transcendente de la acción histórica Por otro lado, hace de la fe, por lo menos en su relación con lo político, una pura instancia previa o, en el mejor de los casos, actual, pero subordinada a las exigencias de la acción política. La fe se convierte en propedética de la acción política y, cuando mucho, se la conserva como motor accesorio del compromiso, pero no como iluminación y critica de los propios hechos históricos, tarea encomendada a las ciencias sociales y, en particular, al análisis marxista. Se supone que basta con los análisis científicos y con las propuestas que de ellos se derivan para emprender las acciones correctas e incluso para formar a los hombres que las van a realizar. La fe despertó tal vez la conciencia y preparó para el salı a la acción política, pero tiene el peligro de interferir con la lógica política y, por tanto, es mejor dejarla en suspenso, cuando no suprimirla El compromiso de fe, la vivencia de la fe quedan abandonados en el supuesto implícito de que basta con amar a los hombres para amar a Dios, de que basta con promover la justicia para hacer el servicio que la fe reclama, de que basta con encarnarse políticamente entre los pobres para servir a Jesús del reino, oculto en ellos. Ante la presión de la acción política o no hay tiempo para el cultivo de la fe o se considera que la acción misma conducira a la profundización de la fe en el compromiso. De todos modos, se permitira y aun se fornentara el cultivo de la fe tanto cuanto promocione la acción política revolucionaria, incluso cuando pone ciertos límites a Esta tanto en el orden de los sentimientos (canje del odio por el amor) como en el orden de las acciones (reducción de la violencia al mínimo necesario). En definitiva, se piensa que bo esencial de la confluencia 
entre el mensaje liberador de la fe y el compromiso político revolucionario está en la lucha por la liberación de los pobres, pero de tal modo que el mensaje debe subordinarse a la efectividad de la lucha y del triunfo. Si esto se logra la fe habrá conseguido su cometido y debe ser así porque la esperanza y la fe son transitorias, mientras que el amor es lo definitivo y más valioso.

El realismo supone y representa una actiud equilibrada que tiene en cuenta tanto lo positivo del aporte evangélico para la propia acción política como los limites de ese aporte, precisamente por la relatividad específica y la autonomia de los dos ámbitos; tiene también en cuenta tanto lo positivo de la acción política para la realización del reino de Dios como los límites que le son propios. Debido a ello considera igualmente lo que de relativamente especffico tienen la acción política y sus resultados políticos (abiertos o cerrados a la transcendencia) y la realización del reino de Dios, no obstante su referencia a determinadas sibuaciones históricas, las cuales pueden ser conformes o disconformes con él. Esta actitud de realismo creyente sostiene que el mensaje evangélico es indispensable para que haya una total liberación de los hombres, de los pueblos y de las estructuras; de modo que, si esta sal se desvanece, se desvanecen también las posibilidades reales de que esa liberación total se vaya historizando. Pero sostiene también que no basta con el mensaje evangélico porque éste no tiene armas propias ni para discernir las causas de la opresión y las propuestas de liberación, ni menos para llevarlas a cabo. El realismo lleva también a la convicción de que ninguna forma polílica se acomoda perfectamente a las exigencias del reino, pero no por ello las iguala a todas o prescinde de todas ellas en razón de un purismo, el cual no tiene sentido en un mundo histórico.

Esto hace que, en primer, lugar, no sea indiferente y pueda, por ejemplo, rechazar en América Latina las distintas formas de capitalismo que han sido las principales responsables de la situación en la que vive la mayoría de la población; esto hace, en segundo lugar, que favorezca a aquellos movimientos políticos que más trabajan no sólo a favor de los pobres y de las mayorias populares, sino que procuran el que estas mayorias populares vayan convirtiéndose en sujetos sociales y políticos más activos.

Todo ello supone, ante lodo, que se ha de potenciar al máximo la fuerza liberadora de la fe, lo cual, negativamente, pide erradicar todo lo que en su predicación, reglamentación y vivencia hay de coartador de su potencial liberador y positivamente exige potenciar entre los creyentes, tanto de las bases como de la jerarquá, lo que la fe misma tiene de exigencia intrínseca de compromiso con la promoción de la justicia. Supone, después, la superación de actitudes ingenuas, lo cual exige un conocimiento cada vez más objetivo y fundado de la mediaciones teóricas y prácticas, a través de las cuales se interpreta y transforma el mundo en una u otra dirección. Junto a ello pide un permanente discemimiento de los signos de los tiempos, el cual para ser correcto deberá incluir en el aporte de la fe el análisis correspondiente. Supone, finalmente, la creación de formas de colaboración en los procesos de liberación, las cuales pueden ser diversas para la Iglesia 
como instiución y para los creyentes, especialmente los laicos, que deseen comprometerse directamente con determinadas líneas políticas y aun con partidos y organizaciones concretos. La opción preferencial por los pobres, entendida en forma realista, es la que debe regir en estas opciones, pero teniendo cuidado de buscar aquellos procesos que más conduzcan a la liberación total, no dejándose engafiar por las mil formas encubridoras que pueden tomar los sistemas de dominación y aun las propias debilidades personales, grupales o institucionales.

Esta breve tipología de actitudes no pretende ser exhaustiva ni como tipología general ni como descripción de cada uno de los tipos. Sirve, sobre todo, al propósito de mostrar a la cuarta de ellas como la más apropiada para ir encontrando el modo concreto más efectivo de conciliar la autonomía de la fe con la exigencia inexcusable de que esa fe promueva elicazmente la justicia y la liberación. La cuarta actioud es la más apropiada porque cumple mejor con una serie de principios que han de estimarse como esenciales en este problema. Tales son: a) la salvación (liberación) desde su principio en la creación se ha de entender como una acción de Dios, la cual debe ser conocida y aceptada consciente y aun temáticamente; b) esa concientización y aceptación supone el máximo ejercicio posible de la fe, que, curnto más sea cultivada, estará en mejor disposición para promover ese proceso de salvación (liberación); c) esa fe debe ser operaliva y lo debe ser en términos de liberación, la cual no puede reducirse a ser una liberación del pecado como culpa, sino que debe ser una liberación del pecado y del mal como obje-! tivaciones dominantes en busca de una libertad que se refleje en el engrandecimiento personal y en la constitución de un mundo nuevo donde se favorezca la existencia del hombre nuevo; d) la operatividad de la fe exige entrar en relación ar-; ticulada con aquellos procesos y aun grupos sociales y políticos que más favorezcan la liberación, supuesto que ésta es siempre un proceso querido por Dios; e) en esa articulación la fe debe aportar lo más específico de ella como fuerza de liberación y de esperanza y también como criterio operativo de lo que no debe ser e iluminativo utópico de lo que debería ser, d) en esta línea el trabajo con las personas y las comunidades cobra un especial significado siempre que se revitalice una fe que viene de Dios. Una fe que está en la persona, pero que debe abrirse a una acción en el mundo, todo ello con el proposito de hacer realidad en las personas y en el mundo la visión y los valores evangélicos como levadura en la transformación de aqueli; f) la opción preferencial por los pobres implica un criterio concreto de discemimiento, en cuanto el mayor bien de las mayorias populares pobres se convierte en la piedra de toque de cualquier proceso y grupo político.

\section{Modelos de relación con los movimientos sociales y políticos}

El predominio de una u otra actitud de las desarrolladas en el apartado anterior lleva a adoptar un modelo en las relaciones prácticas con los movimientos sociales y politicos, que luchan efectivamente por la liberación de las mayorlas populares, y de los pobres. Caben muchos modelos de relación. Teniendo en 
cuenta lo que se ha ido dando hasta ahora se pueden estilizar y esquematizar los hechos convertidos en modelos-tipo. No se trata evidentemente de que todos ellos sean ejemplares o de que todos tengan el mismo valor cristiano; son más bien, modelos en el sentido de que esquematizan toda una serie de comportamientos.

El modelo de sustifución o de anulación supone que lo realmente importante en lo que pretende la teologia de la liberación, es la liberación y, fundamentalmente la liberación socio-económica-política. La predicación y la realización del reino de Dios van dirigidas a esa liberación, que una vez lograda podrá abrirse a otros valores. Lo más necesario ahora y, consiguientemente lo más valioso, es la consecución del triunfo revolucionario. Cuando de lo que se trata es de sobrevivir, las demás cosas, incluso las cosas de la fe, pueden esperar. Si en algún caso tiene sentido el hacerse anatema por los hermanos, es precisamente en éste de trabajar por su liberación, ante la cual todo debe subordinarse. Si incluso quiere defenderse el sentido teólogico de esta postura, habrla que decir que nadie tiene más amor que el que da su vida por los demás y que se puede estar sirviendo a Jesús, aunque no se sepa que él está en el hambriento, en el encarcelado, en el perseguido, y úlimamente en el pobre. Desde esta perspectiva no sólo puede llegar el momento de que se vuelva necesario el romper con la Iglesia instiucional y con mucha mayor razón desobedecer sus prescripciones cuando sea necesario, sino el abandonar el cultivo de la fe, en cuanto este cultivo puede impedir o frenar la lucha revolucionaria. En la formulación extrema, si son excluyentes el ser revolucionario y el ser cristiano, hay que optar por ser revolucionario, ya que ésta es la exigencia ética fundamental y éste es el mandato más imperioso en un mundo donde predomina la injusticia, la explotación y la dominación. La teología de la liberación ya hace bastante con introducir a la lucha política. La pastoral de la liberación lo que debe preparar es que los cuadros mejores abandonen el ministerio de la palabra y se constituyan en promotores de la liberación, en ejecutores efectivos de aquellas acciones que realmente liberen a los pueblos, objetivo último tanto de la acción religiosa como de la acción política. Esto supone, desde luego, una plena subordinación de la organización eclesial, en concreto de las comunidades de base o de otras estructuras eclesiásticas, a la organización política y la subordinación de la fidelidad a la institución eclesial a la fidelidad al movimiento revolucionario, y puede llegar a suponer la sustitución de la vivencia y los valores cristianos por la vivencia y los valores políticos.

A este extremo se puede llegar por dos caminos: uno, por la presión paridista que a la larga ve en la fe cristiana un freno para la revolución; otro, por la presión práclica de la lucha de clases revolucionarias, que, se supone leninistamente, es el mejor antídoto teórico y práctico contra los desvaríos de la religión. En el fondo de todo este proceso hay una secularización revolucionaria de los principios y valores subversivos del evangelio. La fe puede ser el pedagogo inicial que despierte del suefio dogmático y de la inmovilidad popular, pero es, en el mejor de los casos, un estado transitorio, el cual idealmente debe desaparecer y que se tolera mientras no entre en conflicto con la dictadura del partido. En la interpretación más positiva, la lucha revolucionaria es la superación dialéctica de 
la fe, la cual es subsumida en el estudio superior del proceso revolucionario, una vez negadas sus limitaciones y aprovechados sus dinamismos. Lo que le sucede a la antítesis en la síntesis es lo que sucede a la fe en el proceso revolucionario.

El modelo de prestación y apoyo mantiene la autonomía de la fe, procura que esa fe se dinamice y potencie, pero hace lo posible para que esa fe dinamizada y potenciada se ponga al servicio efectivo de los movimientos revolucionarios o, más en general, del proceso socialista. Este modelo no sustenta explícitamente que la fe liberadora sea para el proceso histórico revolucionario de modo que en ese "para" agote su razón de ser, pero piensa que una de las misiones importantes de la fe es la de promover la lucha por la justicia y que esto no puede hacerse de modo efectivo más que optando por alguno de los movimientos políticos, a los cuales se les ayuda religiosa y políticamente y frente a los cuales se limita lo que de crílica pueda tener la fe.

En este modelo no basta con ponerse autónomamente al servicio de los pobres y de los oprimidos, ni siquiera ponerse al servicio del proceso revolucionario desde una posición independiente, sino que se busca ponerse al servicio de aquella organización concreta, que en cada caso resulte ser la vanguardia del proceso revolucionario. No se estima en mucho lo que la fe y aun la instiuución eclesial puedan hacer autónomamente en favor de los pobres y de la revolución. Se prefiere potenciar a las fuerzas que realmente pueden tomar el poder o mantenerse en él, perdonándoles aquellas debilidades que la lucha política por el poder lleva necesariamente consigo. No supone esto una manipulación de la fe, por lo menos en principio e idealmente. La promoción de la justicia a través de una opción política no tiene por qué separarse de la fe ni menos suponer una mengua de ésta; al contrario, siempre en principio e idealmente, cuanto más vigorosa y encamada sea la fe, mayor será su contribución a la causa de la justicia. Más aún, la elección partidista está hecha desde la fe.

Efectivamente, la fe impulsa al compromiso político; impulsa, en segundo lugar, al compromiso polltico revolucionario en aquellas situaciones donde la injusticia estructural es el carácter definitorio de las mismas; impulsa, finalmente, a ser efectivo y, por tanto, a apoyar aquellas instancias capaces de combatir la injusticia y de instaurar un nuevo orden social. Es la fe la que excluye la pertenencia a partidos que, de una u otra forma, cohonestan el status quo y es la fe la que impulsa a ponerse al servicio de los partidos que combaten ese status quo y que tratan de sustituirlo por otro que favorezca las causas populares. Esto puede hacerse desde una opción personal, intengrándose plenamente en un partido político o en un movimiento revolucionario, al cual tratará de impulsar en su esfuerzo transformador, sin prestar atención prioritaria a que en los medios y en los objetivos inmediatos se hagan presentes los valores evangélicos. Puede hacerse también desde una opción de grupo cuando una comunidad de base o un conjunto de ellas se ponen al servicio de una determinada organización política sin abdicar de su vocación cristiana, pero dedicando toda su acción temporal al apoyo de la misma, en lo que ella determine como prioritario. Puede hacerse también desde una 
opción institucional cuando una parte de la Iglesia institucional o toda ella se enfrenta contra una determinada opción política y se pone a favor de otra opción social o política, como en el caso de la jerarquía polaca mientras se enfrentó más o menos abiertamente al régimen comunista y apoyó el sindicalismo de Solidaridad, mostrando con ello que algo asf es posible en la dirección contraria en la cual se movió la Iglesia polaca. En todos esos casos no se trata de crear una tendencia crítica disidente de cristianos dentro del partido o del movimiento revolucionario, porque se estaría más por lo común que por lo diferenciado, más por sumar que por restar.

El modelo de colaboración social se fundamenta en la convicción de lo que es especílico de la fe y de la institución eclesial y de lo que es su limitación. Lo especílico de la fe y de la Iglesia no es la promoción de aquellos aspectos políticos y técnicos, necesarios para la realización del reino de Dios en la historia, pero que no agotan la constitución del reino ni son posibilidad inmediata para el creyente en cuanto creyente o para la Iglesia en cuanto Iglesia.

Los aspectos políticos y tócnicos del reino de Dios, así como los cienufficos, culturales, lúdicos etc., no son objeto especlfico de la fe en cuanto son formalmente tales, sino en cuanto favorecen o desfavorecen el anuncio del reino de Dios. Dicho de una manera inexacta en su exclusividad, pero acertada en su direccionalidad, podría decirse que en la unidad del reino de Dios, el que "Dios reine" es el objetivo de la salvación (liberación), lo es el que el reino sea de Dios; pero cómo ha de configurarse, el reino, en tanto que realidad sociohistórica, es el objetivo de la historia En la historia de salvación se conjugan para bien y para mal los dinamismos de la historia y los dinarnismos de la salvación; hay entre ellos una mitad estructural de modo que se codeterminan mutuamente hasta el punto de que esa unidad, más que los elementos que la constituyen, es el reino de Dios, es la historia de la salvación. Pero esto no obsta a que esos elementos sean distintos y que necesiten permanecer distintos para que la unidad tenga la riqueza y la autencidad que le corresponden. Atendiendo sólo al elemento político - pero lo mismo valdría en distinto grado para otros elementos como lo científico, lo tecnológico, lo cultural, etc.-, puede decirse que determina y es determinado por el elemento cristiano sea cual fuere el modo como se realiza esa determinación, pero no por eso se confunde con él ni se sustenta, ni menos se realiza, por las características y los dinamismos del elemento cristiano. Lo político siendo político determina y es determinado por lo cristiano siendo cristiano no en forma de paralelismo ni necesariamente en forma de causalidad, aunque por simplificar la cuestión podria aceplarse que se da cierta interacción.

Aceptando ese esquema explicativo fundamentado en la unidad estrucural y en la codeterminación de varios elementos, los cuales no son sin más "elementos," sino "elementos -de" la unidad estructural, pero que tampoco son la pura unidad del "de," sino algo que tiene sus notas propias por ser tal elemento, podemos entender por qué el modelo de colaboración social sin romper la unidad con lo político ampoco se confunde con él ni se siúa en el mismo plano. 
Esto es más obvio en cuanto la salvación (liberación) se refiere a las personas y en ello no hay problema especial. La persona debe ser liberada del pecado, de la concupiscencia en sus múltiples formas (de la carne, del dinero, del poder) y debe, en su interioridad asf como en su comunicación personal con los demás, convertirse en una criatura nueva, en un hombre nuevo, concretamente en otro Cristo, de modo que en la nueva vida ya no sea el yo viejo, sino Cristo quien sea principio de la vida, de los modos de ser y de los modos de actuar. Ya desde este punto de vista es medible la diferencia entre el aporte de lo cristiano y el aporte de lo político. Pero esto es también comprobable en la dimensión colectiva de la fe más allá de la dimensión personal o interpersonal. Los hombres liberados cristianamente pueden hacer mucho por la revolución o el cambio social, pero no se reduce a eso la misión social de la fe y de la institución eclesial. Veámoslo.

No puede negarse que la institución eclesial es una fuerza social. Prescindiendo ahora de toda consideración de fe, es una institución formada por millones de hombres enlazados entre si dentro de un orden jerárquico, que tiene una doctrina propia y múltiples canales de acción frente a otras fuerzas sociales. Esta fuerza social le ha llevado con frecuencia a la tentación de convertirse en fuerza política $\mathrm{Si}$, para entendernos, hacemos un corte entre lo que es propio de la sociedad y lo que es propio del Estado -pasamos por alto la precisión y la actualidad de esta situación y podramos hablar también de sociedad civil y de sociedad polícica-, debemos decir que la institución eclesial debe situarse formalmente en el ámbito de lo social, en el ámbito de la sociedad civil. Si por otra parte hacemos también un corte entre lo que es el poder político y lo que es el poder social, esto es entre el poder que viene de, va a y está en la compleja estructura estatal y el poder que viene de, va y está en la compleja estructura social, debemos decir que la institución eclesial debe situarse formalmente en el ámbito del poder social. Pues bien, el modelo de colaboración social, a través del cual la fe y la institución eclesial quieren contribuir a la realización del reino de Dios, y, en concreto al cambio social exigido por la injusticia de las estructuras, se atiene a que la institución eclesial es y debe ser una fuerza que se mueve directa y formalmente en el ámbito de lo social y no de lo estatal y que echa mano del poder social y no del poder político para realizar su misión.

Hay o puede haber una eficacia autónoma de la Iglesia y de la fe en la configuración de lo social. No sólo es que la Iglesia sea en sf una fuerza social, la cual ejercida evangélicamente, no es otra cosa que el despliegue de su misión, sino que si pretende ser una fuerza política, sea dominando a otras fuerzas políticas o poniéndose a su servicio, es como la sal que pierde su sabor. Sin profundizar ni extendernos en las razones de que esto ocurra -y el que haya ocurrido siempre deberia ser ya un buen aviso probatorio- se puede apelar a aquella sentencia esencial del evangelio, que asegura que el hijo del hombre no ha venido a ser servido sino a servir, que, por tanto, el hijo del hombre y sus discípulos no deberán actuar como los sefiores de este mundo que pretenden dominar. En estas sentencias se sefiala la diferencia profunda entre el poder político y la fuerza social, entre la 
dinámica de la dominación y la dinámica de la liberación entre la ambición del mando y la sumisión de servicio. No por ello ha de renunciarse a la eficacia, pero la eficacia en esta caso viene de la presión social, a través de la palabra y del gesto, y no del manejo del poder político. Cuando esta presión social se pone entera en favor de las mayorias populares y del movimiento popular con el consiguiente choque frente a las clases y estructuras dominantes, se entrará sin duda en conflicto, pero no en un conflicto por ir en contra de nadie, sino por ir en favor de las mayorias populares oprimidas. Es una labor parcial, que no agota todo lo que debe hacerse por otras instancias, pero es una labor propia de la Iglesia como fuerza social, y una labor en la que la fuerza de la fe aporta algo insustituible. Ejemplos como el de Monsentor Romero, con su Iglesia de San Salvador, muestran que este modelo tiene su peculiaridad y su eficacia.

Con este planteamiento se salva la especificidad y la autonomía de la fe y de la instimción eclesial. Ni la Iglesia, ni ninguna parte de ella, ni siquiera un cristiano en tanto que cristiano ha de subordinarse a ninguna instancia polftica y, desde luego, a ningún gobierno. Especialmente esto es válido de la Iglesia como institución y de sus distintas partes, no excluidas las comunidades de base. Una cosa es el compromiso social en favor de la justicia y otra la subominación a otras organizsciones, sobre todo de tipo político, de las cuales se reciben órdenes o consignas de actuación. Puede que la acción o la linea determinada autónomamente por la Iglesia o por partes de ella favorezcan más a una organización que a otra, pero esto debe ser como una consecuencia, no como un principio. No es aceptable la identificación de la opción en favar de los pobres con la opción en favor de la revolución, ni la opción por la revolución con la opción por una determinada organización revolucionaria, ni la opción por una determinada opción revolucionaria con la opción por una determinada vanguardia El presumir estas identificaciones es un error de enormes consecuencias.

Hay una estricta gradación y el compromiso formal de la Iglesia debe ser por las mayorlas populares desde el evangelio, quedando su compromiso con el resto de escalones condicionado a un discernimiento permanente. S6lo en casos excepcionales se da la ocasión para que el compromiso institucional pueda sobrepasar el nivel de favorecer los cambios estructurales, requeridos por las mayorias populares para ir realizando su propia liberación. Monsefior Romero hablaba de la posible y peligrosa absolutización de las organizaciones populares, cuanto más de la subordinación a cualquier organización popular absolutizada.

Soblo la desconfianza en la eficacia histórica de la fe puede llevar a abandonar su crecimiento para dedicarse al crecimiento de otras instancias. Esas otras instancias políticas son necesarias, como lo son tambien las instancias cientificas, tecnológicas, etc. La fe tiene una palabra sobre ellas, unas veces de denuncia y otras de aliento. La fe puede lanzar a un trabajo estrictamente politico en cuanto la poLítica puede entenderse como un modo más universal de vivir la caridad. Pero diffcilmente se dará el caso en que sea més benificioso para el pueblo y las mayorias populares el que la Iglesia abandone la predicación y la realización de la fe en 
favor de un compromiso político. Hay tanto que hacer en la dimensión de lo social y desde lo social se puede presionar tanto sobre lo político, que no debe caerse fácilmente en la tentación de transformar la dimensión social de la fe en dimensión política. La política, en última instancia, se mueve en el plano de lo supraestructural, mientras que la acción social se mueve en el plano de los sujetos humanos y también en el de lo estructural. La vida está más en lo social que en lo político, y lo social representa un lugar más natural para la Iglesia a la par que representa una tentación menor. Este recurso a lo social no se hace en la linea de separarse del mundo o de rehuir el compromiso; no se trata de potenciar a la Iglesia o evitarle peligros, se trata más bien de contribuir a la historización del reino, a su realización histórica en lo que es más propio de la Iglesia y en lo que más necesitan los hombres. No se pueden hacer separaciones estrictas. Se trata más bien de acentos. Pero los acentos son importantes.

Esta atención a lo social, en vez de a lo político, radica en el carácter social no político de la institución eclesial como en el carácter más real de lo social, en el carácter más participataivo de los hombres en lo social y a través de lo social. Por ejemplo, está codo el campo de lo sindical o de lo educacional, donde la fe puede promover $e$ inspirar estilos de acción de manera eficaz. Aunque nominalmente se da la posibilidad de que haya partidos o gobiernos de inspiración cristiana, en realidad esto no se da y lleva enormes peligros de manipulación del cristianismo. Asi como pueden darse políticos de inspiración cristiana, es improbable que se den partidos y gobiernos de inspiración cristiana, mucho menos confesionalmente cristianos. En cambio, es más hacedero, aunque no sea fácil, ponerse en relación con fuerzas sociales para impulsarlas y orientarlas desde una inspiración cristiana. Todo ello reperculirá últimamente en la esfera de lo político, sobre la cual debe presionarse como fuerza social y a traves de las fuerzas sociales.

\section{Le teología de la liberación y los movimientos marxistas}

No se trata aqur de discutir la relación de la teologia de la liberación con el marxismo de un modo general. Esto ya se ha hecho en repetidas ocasiones y desborda, además, los límites de esta presentación. De lo que aqui se trata, a modo de ejemplo, es de situar al movimiento de la teología de la liberación en relación con las distintas formas sociales y políticas de orientación marristas, que pretenden el cambio sociohistórico de América Latina

La teologia de la liberación ha surgido en buena medida de la experiencia del desastre humano que ha supuesto la vigencia de distintas formas de capitalismo en América Latina. Esa experiencia es en su inmediatez una experiencia de la pobreza y aun de la miseria injustas, que se abaten sobre la mayor parte de la población. Se trata primeramente de una experiencia ético-religiosa, semejante a la que tuvo Moisés, cuando se percató de cómo vivía su pueblo en Egipto. El atribuyó esa situación a la opresión del faraón y, más en general, de la clase dominante egipcia. La teologia de la liberación en América Latina atribuye también a los ricos y poderosos la situación que hace clamar a los pobres con un clamor que llega hasta el cielo. 
Es una atribución de tipo ético-religiosa, quizá referida más a las personas que a las estructuras, a voluntades personales más que a las leyes sociales. Serian los "ricos" los responsables de la situación de los "pobres," no sólo porque no los socorren como fuera debido - punto tradicional en la predicación usual histórica de la Iglesia-, sino porque de una u otra manera serían responsables y causantes de la pobreza. De ahf la espontánea reacción ético-religiosa de ponerse a favor de los pobres y sólo como consecuencuia en contra de los ricos.

Esta experiencia fundamental y fundante se encuentra con una teorla que pretende explicar cientfficamente ese fenómeno y que propone no sólo una alternativa al mismo, sino un modo de superación real. Es el caso del marxismo; pero es aquella parte del marxismo que explica los mecanismos de explotación del capitalismo, que propone un sistema económico distinto con su correspondiente sistema político y que arbitra una praxis revolucionaria capaz de derrocar el sistema capitalista y de implantar el sistema marxista. Se tiene, además, la vivencia de que sólo los movimientos marxistas están haciendo algo efectivo por terminar con la etapa de explotación capitalista. De ahi se concluye que, si se desea hacer algo efectivo en la superación de la injusticia y en la liberación de las mayorías populares se debe sacar provecho de lo que el marxismo está haciendo tanto en el campo teórico como en el campo práctico. En un primer momento se apreciaron más las ventajas de los aportes del marxismo que las dificultades tanto inmediatas como mediatas que de él pudieran desprenderse.

En un primer momento, la teologín de la liberación, en su afán de ponerse al servicio de la liberación de las mayorias populares, se hizo radicalmente anticapitalista y en esto coincidió con las posiciones marxistas. La Iglesia universal en su doctrina social habla también ido logrando la persuación de que un capitalismo no moderado por principios morales estaba siendo una verdadera plaga para la humanidad Tanto la Gaudium et spes del Vaticano II como las últimas enciclicas papales han denumciado cada vez con mayor penetración y severidad los desmanes del capitalismo. Pero lejos de pensar que el capitalismo era intrinsecamente malo, se ha querido ver en él el modelo adecuado para el desarrollo democratico de los pueblos. Debe ser corregido, debe ser reformado, segín las orientaciones de la moral cristiana, pero no tiene por qué ser abolido. Máxime, que la otra alternativa, la del socialismo real, le ha parecido a la Iglesia mucho peor, sobre todo para ella misma, pero también para los pueblos. Se ha comparado la situación de los países capitalistas noratlánticos con la situación de los parses donde se ha impuesto un régimen socialista y de ello se ha concluido que era de todo punto incomparablemente mejor lo que ocurria en aquellos que lo que ocurían en éstos. Se tenf́a muy poco en cuenta lo que sucedfa en el resto del mundo, donde otras formas de capitalismo daban como resultado situaciones desastrosas en lo económico, en lo social y en lo político. Por todo ello se pensaba que una reforma del capitalismo seria el sistema adecuado para resolver los problemas y que ese sistema supondria el mejor contexto en el cual podrí consolidarse el ser de la Iglesia y de su misión. Puede decirse asi que la doctrina social de la Iglesia es un intento de reforma y de humanizeción del capitalismo. 
Pero la experiencia liberadora en América Latina era distinta El capitalismo aparecería en sus realizaciones históricas, no sólo como intrinsecamente malo, sino como sustancialmente antievangélico. El capitalismo era irreformable. Podría conseguirse que hiciera males menores, pero no podía concebirse como el modelo ideal en el que el hombre fuera verdaderamente hombre y en el que las mayorías populares tuvieran la posición que merecen a los ojos de Dios. El capitalismo es bueno para los fuertes y los débiles pueden aprovecharse de él en tanto que los fuertes se enriquezcan más y distribuyan algo de su riqueza. Esto no es evangélico. Lo evangélico, la exigencia del reino de Dios, es que se alcance un sistema en que las mayorías populares, los pobres, sean el verdadero sujeto de la historia, si no por ser pobres, al menos por representar a la mayoría de los pueblos y a la mayoría de la humanidad. Había una experiencia real del capitalismo y de sus males y no habia una experiencia real del socialismo y de sus males. Esto hace que la teología de la liberación, en vez de pretender y propiciar una reforma del capitalismo, se esfuerce en conseguir una reforma del socialismo. El socialismo, se pensaba, es un sistema más conveniente para la causa de los pobres y es, consiguientemente en virtud de la opción preferencial por los pobres, más congruentes con la realización histórica del reino que debe impulsar la fe cristiana.

Se pasa asi de una posición anticapitalista a una posición prosocialista. Lo primero es la posición anticapitalista, al percatarse no sólo vivencialmente, sino racionalmente de que los males de América Latina no vienen de la dureza de corazón de los ricos, sino de la estructura misma del sistema, tanto en su configuración interna como en su conexión con el capitalismo mundial, especialmente con el de Estados Unidos, que se constituye en el guardián polftico y militar de ese orden. El anticapitalismo lleva al antiimperialismo norteanericano. La liberación de América Latina debe ser no sólo una liberación del sistema capitalista, sino también una liberación de la dominación norteamericana. Apoyar las causas y los procesos anticapitalistas y antiimperialistas se convierte as en uno de los modos de acción histórica de la teologia de la liberación. Asf se llega a una colaboración obvia con los movimientos revolucionarios marxistas que están entregados totalmente a esa tarea, no obstante que se aprecien defectos tanto en la teorla como en la practica de los mismos. Sin embargo y en consecuencia con lo anterior, se es anticapitalista, pero no se es de la misma forma promarxistin, cuanto menos se es maxista. La teologia de la liberación y los movimientos que están bajo su inspiración es y son cristianos, aunque sus distintrs actitudes y los diversos modelos frente al cambio social los pueden llevar a ciertas desviaciones prócticas, que a la larga pueden transmutar su realidad. Pero en este caso se ha abandonado lo que es la leologia de la liberación; por lo tanto no es justo atribuirle lo que ya no es propio de ella.

Uno de los puntos en los que tiende a darse una convergencia es en la cuestión de los pobres por un lado y de las clases oprimidas por otro, de modo que la lucha de clases se conviente tanto para la teologia de la liberación como para el marxismo en un punto de coincidencia. Se piensa que la preocupación de la teolo- 
gra de la liberación por los pobres, a la hora de buscar efectividad real, debiera inclinarse naturalmente a la interpretación clasista de esa categoría biblica y, consecuentemente a una práctica políica de lucha de clases, la cual es esencial al marxismo, al menos en su forma más ortodoxa. Sin embargo, conviene hacer ciertas aclaraciones para no caer en simplismos. Tal vez no siempre se ha tenido un cuidado en este punto $y$, aunque los té́logos de la liberación no han solido caer en confusiones, tal vez en algunas acciones prácticas y en algunos movimientos de base si se ha podido caer en ellas y también en exageraciones.

Ante todo, no está de más recordar el famoso texto de Marx referido a la lucha de clases.

Por lo que a mí se refiere, no me cabe el mérito de haber descubierto la existencia de las clases en la sociedad ni la lucha entre ellas. Mucho antes que yo, algunos historiadores burgueses habian expuesto ya el desarrollo histórico de esta lucha y algunos economistas burgueses la anatomfa económica de éstas. Lo que yo he aportado de nuevo ha sido demostrar. 1) que la existencia de clases sólo va unida a determinadas fases históricas del desarrollo de la producción; 2) que la lucha de clases conduce necesariamente a la dictadura del proletariado; 3) que esta misma dictadura no es de por sI más que el tránsito hacia la abolición de todas las clases y hacia una sociedad sin clases (Carta de Marx a Weyderneyer, 5 de marzo de 1852).

Del texto se desprende que las clases y la lucha de clases se dan historicamente de una cierta manera espontónea, lo cual ya habla sido descubierto como una cierta ley de la historia por autores premarxistas. Este punto es importante porque la teologia de la liberación habria reconocido esta interpretación, hasta cierto punto neutral, de que efectivamente se están dando clases y lucha de clases, con el agravante de que la situación en América Latina muestra que son las clases dominantes las que han iniciado la lucha y la violencia no sólo para construir las clases dominadas, sino para mantenerlas en la dominación, de modo que las incipientes respuestas historicas de las clases dominadas son eso: respuestas a una violencia anterior, respuestas provocadas no sólo por la situación objetiva de las clases dominadas, definida por la miseria y la injusticia, sino por la percepción de que esa sibuación se debe a la violencia cometida contra ella

Del marxismo, entonces, se ha tomado que ese fenómeno de las clases primero y de la lucha de clases después se da específicamente en una determinada fase histórica del desarrollo de la producción; para el caso latinoamericano esa fase histórica sigue siendo la fase actual, cosa que tal vez no se da en los paises más desarrollados donde la producción ha tomado otros derroteros. Del maxismo se ha tomado tambien - y esto muy en consonancia con la inspiración cristiana- que es necesario llegar a la abolición de las clases, conducente a una sociedad sin clases, tal como en lengugje metaffarico se anuncia con fuerza en el mensaje bßblico.

Todos esos puntos de convergencia tienden a concluir que los pobres de los que habla la Biblia son el proletariado del que habla Marx y que, por consi- 
guiente, el modo de liberación de esos pobres pasa por una dictadura del proletariado. Sin embargo, la teología de la liberación más madura y crítica no acepta estas proposiciones. Entre decir que los pobres biblicos son las clases dominadas, entendidas éstas como categoría socio-historica, sea de los pensadores burgueses o marxistas, y el asegurar que los pobres biblicos no tienen nada que ver con esas clases, la teología de la liberación sostiene una posición mucho más diferenciada

Los pobres biblicos tienen muchas semejanzas materiales con las clases oprimidas, pero no se identifican con ellas por las siguientes razones: 1) aunque el grueso de los pobres bíblicos y la razón de su pobreza tienen mucho que ver con la clases oprimidas, el concepto de pobre brblico es más amplio y, en concreto, no puede identificarse con el proletariado estrictamente entendido; 2) la especial preferencia de Dios por los pobres no se reduce a su liberación puramente socio-económica sino que atiende a su condición personal y a su liberación histórico-transcendente; 3) los pobres de Yahvé, teniendo como tienen una estricta realidad socio-histórica, no se reducen a ser una categoria socio-historica; 4) los pobres para que contribuyan plenamente como sujetos activos a la liberación integral propia y de los demás, sin abandonar su condición histórica, deben incorporar el espíritu del mensaje cristiano de modo que sean auténticamente pobres con espiritu; 5) aunque puede haber tramos de coicidencia en la lucha histórica con las clases sociales oprimidas, lo que las clases oprimidas pueden hacer con sus luchas revolucionarias, no es suficiente ni para la liberación integral ni siquiera para la liberación exclusivamente histórica; 6) esa coincidencia difícilmente pasal por la dictadura del proletariado, tal como se ha venido dando históricamente a través de las vanguardias de los partidos.

Esta posición diferenciada lleva a conclusiones prácticas. La teología de la liberación no puede menos de aprobar y en muchos casos de apoyar a aquellos movimientos marxistas auténticamente revolucionarios y no puramente burocráticos, sobre todo en lo que tienen de preocupación y trabajo por los pobres tanto a la hora de la denuncia de las opresiones del sistema capitalista como a la hora de procurar eficazmente la superación de las distintas formas de miseria, injusticia y opresión. Esto se da sobre lodo cuando se trata de organizaciones populares, respecto de las cuales el marxismo y la toma del poder no son elementos esenciales, sino aspectos instrumentales en la lucha para que las mayorias populares se conviertan en sujetos activos de su propio destino histórico. Pero al mismo tiempo la teología de la liberación no puede menos de diferenciarse de las políicas manxistas y esto de diversas formas. La teología de la liberación pretenderé, ante todo, el robustecimiento creyente de las mayorias populares, lo cual no implica su debilitamiento social comprometido, pero sí su responsabilización en to que tienen de sector preferencialmente elegido por Dios para traer a la historia una liberación integral, que va más allá de un planteamiento exclusivamente político. En este sentido hay una autonomfa que debe ser respetada. La teologia de la liberación pretendera, también, robustecer el aporte de la fe cristiana al cambio social par cuanto, aun sin subordinarse a ninguna instancia pollíca, la 
fe, los que viven la fe y la Iglesia tienen una fuerza propia que debe ponerse autonomamente al servicio de la realización histórica del reino. Finalmente, la teología de la liberación impulsará el que los movimientos políticos y/o sociales, los cuales dicen estar al servicio de las clases oprimidas, lo estén de hecho y primariamente, sin subordinar ese servicio a la consolidación institucional de esos movimientos y, además que en la elección de los medios y en la jerarquía de los valores se acomoden a lo que la fe cristiana propone como espíritu de woda liberación posible.

Con estos principios la teología de la liberación no sólo desecha el anatema polf́tico e ideológico que pesa sobre el marxismo y sobre cualquier posición progresista en muchos círculos de América Latina, no excluidos amplios sectores populares, sino que se esfuerza en colaborar con el marxismo de una manera positiva. Esa colaboración no llega a aceptar puntos más bien filosóficos del marxismo en lo que pueda tener de sistema materialista cerrado, sino que se ciffe en lo tećrico a la utilización más bien heurística de lo que el marxismo tiene de análisis científico en cuestiones socio-historicas y específicamente economicas y en lo práctico se dedica a promover todo lo que de positivo puede haber en los movimientos populares y en los movimientos de liberación, sin olvidarse de criticar lo que de malo pueda haber en ellos o de impulsar aquellos elementos que pueden ser mejorados. Se da así una clara distinción con otras posiciones dentro de la Iglesia y ello constituye uno de los puntos de debate frente a la teología de la liberación. Pero para que ese debate sea útil no puede llevarse a cabo caricaturizando la posición global de la teologia de la liberación, tal como ocurre en la primera de las instrucciones de la Sagrada Congregación para la Doctrina de la Fe sobre la teología de la liberación. Ni el marxismo ha desfigurado la interpretación que la teología de la liberación hace de los puntos esenciales del mensaje cristiano, ni aquélla mantiene una posición ingenua ante la práctica política de los distintos movimientos marxistas. Más bien se mueve con distintos matices y diferentes tendencias en el marco aqul descrito.

\section{La teología de la liberación y la violencia}

La teología de la liberación no sólo es relacionada con la lucha de clases, sino más específicamente con la violencia revolucionaria. Con la incitación al odio, la lucha de clases se extendería y radicalizaria y, desde ella, la violencia revolucionaria serfa el arma propia de las masas en la conquista del poder. Odio, lucha de clases, violencia revolucionaria no sólo serían toleradas en la teología de la liberación, sino que además serían provocadas por ella. Sin embargo, si esto no es así de simple en el marxismo, lo es mucho menos en la teología de la liberación.

Al contrario, la teologia de la liberación surge de la vivencia profunda del estado de violencia y de los actos de violencia, que constituyen el entramado social de América Latina y se propone con todas sus fuerzas la anulación de esos actos y la superación de ese estado. Desde este punto de vista, la teología de la liberación pretende ser una instancia desideologizadora de la violencia. De ningún 
modo se atiene a aquel principio de que la violencia es mala, venga de donde venga. Ciertamente puede aceptar que todo acto de violencia, todo acto que por la fuerza haga algún mal, no es bueno, pero para afurmar inmediatamente que la violencia se predica y se afirma de muchas maneras y que todas esas maneras de ninguna forma son univocas ni menos uniformes. Hay unas violencias peores que otras. La moral clásica, tan gustosa de distinguir especies y matices en los pecados desde muchos puntos de vista, debiera utilizar la misma precisión al hablar de la distinta gravedad de las diversas formas de violencia. La teología de la liberación pretende formalmente y en última instancia que se supere toda forma de violencia, que desaparezca la violencia en todas sus formas, pero no por eso permile el que, so pretexto de que toda violencia es mala, las más graves formas de violencia se consoliden. Por eso se pregunta por las distintas formas de violencia y por sus efectos, según el criterio y la perspectiva desde la cual enfoca sus problemas, el de la opción preferencial por los pobres, el de la situación de las mayorias populares.

Desde esta perspectiva, la cual está en plena consonancia con el mensaje bíblico, la teologia de la liberación atiende, en primer lugar, a aquella violencia que se abate sobre las mayorias populares en forma de injusticia estructural. Se trata de aquella injusticia que afecta al conjunto de las estructuras sociales, económicas, politicas, culturales, etc., en las cuales forzosamente ha de vivir el hombre y que por su propia estructuración le impiden vivir humanamente. No se trata sólo de que esas estrucuturas no le den facilidades para llevar una vida humana, sino que se lo impiden al privarle por la fuerza, muchas veces legalizada e institucionalizada, de aquellos medios indispensables para poder vivir como hombre. La opresión en todas sus formas y, más en general, todo modo de injusticia estructural, es la mayor de las violencias por cuanto afecta a la mayoria de la población y la afecta en aquello que le es más sagrado y profundo: la conservación y el perfeccionamiento de la propia vida. Y es la mayor de las violencias, no obstante que se presenta con modos y maneras desprovistos del dramatismo aparente de otras formas de violencia. Todo lo que la teología de la liberación denuncia como pecado social, que en la situación de América Latina es en gran parte resultado del capitalismo imperante, tanto en la relación centro-periferia, norte-sur, como en su reflejo correspondiente dentro de cada país, se considera como violencia y origen de violencia. El reflejo principal, pero no único, de esta violencia es la situación de pobreza y miseria que afecta de forma fundamental no a la calidad de la vida, sino al hecho mismo del vivir.

La represión es también parte de esta violencia estructural y, cuando no es una represión puramente ideológica de engaffo por la imagen y la propaganda, sino que se convierte en represión policial o en represión a través de los escuadrones de la muerte, tiende a cobrar formas extremas, las cuales subjetiva y objetivamente, tienden a aniquilar a sus víctimas. El estado de violencia en que se está en razón de la injusticia estructural no puede ser mantenido más que por la fuerza injusta de una violencia sobreantadida. Esta represión trata de impedir la lucha con- 
tra la injusticia ya sea preventivamente, ya sea con un desatado terrorismo de Estado o de clase, cuando ya han surgido los movimientos revolucionarios y aun anteriormente cuando ha surgido la protesta popular contra una situación que se va haciendo insostenible, no sólo por la hiriente desigualdad entre los pocos que lo tienen todo y las mayorias que apenas tienen nada, sino por los mecanismos de acumulación y explotación que han dado origen a esa situación. Estas descripciones no son fantasías académicas, sino constataciones de las formas como se presenta la violencia en muchos pueblos de América Latina.

La teologia de la liberación hace de esta situación un dato primario. No sólo se percata de que es una realidad que afecla profundamente a la mayor parte de la población, sobre todo en los países más pobres, sino que la estigmatiza como un gravísimo pecado. Lo que el Exodo plantea como el gran clamor de un pueblo que llega hasta la presencia de Yahvé, como un reclamo creciente de liberación, lo hace asimismo la teología de la liberación, la cual lee en los mismos términos la situación latinoamericana. La lectura del Exodo en este estudio del análisis lleva, en primer lugar, a entender como justicia primaria el anhelo de liberación de este pueblo asi oprimido y reprimido y, en segundo lugar, a buscar, como en el caso de Moisés, aquellos medios efectivos que puedan traaer la liberación. Pero en el momento actual hay una separación histórica de las dos dimensiones de Moisés, la política y la religiosa. La teología de la liberación se sitúa más bien en la dimensión religiosa, pero busca la relación con la otra dimensión política, que en su radicalidad sólo es mantenida por los movimientos revolucionarios.

La teología de la liberación, entonces, acepta en principio la moralidad y aun la coherencia cristiana de la violencia liberadora de las otras formas radicales de violencia, siempre que se dé en el contexto y con las condiciones debidas. Sigue en esto la misma línea de la moral clásica sólo que de una forma más rigurosa y restringida al permitir ciertas formas de violencia sólo frente a la violencia estructural, represiva y opresora. La violencia de la injusticia estructural, sobre todo cuando llega a extremos de impedir la realización de la vida humana y de cerar todos los caminos menos violentos de buscar el remedio, es un mal máximo que puede y aun debe ser combatido con medios eficaces, incluida la lucha armada. En la caracterización del mal la teología de la liberación resala el carácter social de la injusticia estructural más que el carácter político (tirania), al cual solia referirse la moral clásica, considerando que lo social es más definitorio que lo político. Pero, no obstante la licitud limitada de la lucha armada, ésta es siempre un mal, y sólo puede ser usada en proporción con el mal mayor que se quiere evitar. Ese mal ha de medirse sobre todo en relación con los dafíos que a corta y larga distancia se den para las mayorias. Cuando, en cambio se da una subordinación del bien de las mayorías populares a la conquista del poder políico por parte de un movimiento revolucionario o al mantenimiento en él, queda invalido el derecho a la lucha armada.

Por otro lado, no cualesquiera medios violentos pueden ser empleados. Hay 
medios tan intrínseca y totalmente malos, que su utilización está vedada. De ahí que la violencia revolucionaria no debe lomar nunca la forma de terrorismo. Se entiende por terrorismo aquel conjunto de acciones hechas contra personas indefensas de forma violenta que ponga en peligro su vida o su integridad física. Algo no es terrorismo porque proceda de grupos cualificados anteriormente como terroristas, sino que el terrorismo y el terrorista deben medirse por las acciones perpetradas. Desde este punto de vista hasta gobiemos legalmente establecidos pueden ser estrictamente terroristas en distinto grado. Los movimientos revolucionarios caen también con frecuencia en la tentación de cometer acciones terroristas.

Tampoco es aceptable propiciar como condición subjetiva, favorecedora de la violencia revolucionaria, el odio en ninguna de sus formas. El enemigo no deja de ser persona humana, a quien se pretende liberar de su papel de opresor o represor violento. La diffcil tarea de amar al enemigo, incluido el enemigo social, no deja de ser un desafio para el cristiano. Ciertamente las clases no son personas que se pueden amar u odiar, pero hay el peligro de introducir en el rechazo de la clase el rechazo de las personas que pertenecen a ella. La lucha revolucionaria no debe hacer olvidar que el evangelio está más en favor de la paz que de la guerra, más del servicio que de la dominación, más del amor que del enfrentamiento.

Es posible que la teología de la liberación haya sido en algunos momentos y en algunos lugares un tanto ingenua sobre las posibilidades reales de la violencia revolucionaria, sobre su mezcla de males y de bienes. Puede aceptarse que los cambios revolucionarios necesarios en América Latina no pueden conseguirse sin movimientos traumáticos. Todo el cuerpo social y político está organizado con vistas al bienestar y al dominio de las élites dominantes y al servicio de los imperialismos, lo cual, si se quiere cambiar urgente y drásticamente, implica transformaciones que encuentran una resistencia fortísima Pero en estos casos no cabe pasar fácilmente de la necesidad ética a la posibilidad política. Los triunfos revolucionarios en Cuba y Nicaragua hicieron que se viera como inminente un cambio revolucionario global en toda América Latina o, al menos, en algunos parses. Los fracasos en Argentina, Unuguay, Chile, Bolivia Brasil el feroz desangramiento ocurrido en Colombia y Guatemala, la dureza de la lucha en El Salvador han hecho que no se pueda caer en ingenuidades políticas. Los fundamentalismos religiosos pueden llevar a suicidios sociales.

Por otro lado, el uso de la fuerza para mantenerse en el poder y los escasos resultados económicos van haciendo más cauta a la teologia de la liberación. Ciertamente regimenes levemente reformistas no eslán trayendo una minima liberación a las mayorías populares ni las democracias políticas están generando democracias sociales ni siquiera están produciendo la ruptura del círculo de la miseria y de la injusticia estructural. Por lodo ello, aunque la teología de la liberación propende a simpatizar más con las organizaciones populares y con los movimientos revolucionarios, no por eso cae en el simplismo de identificar su propósito utópico con las formas concretas que aquéllas y éstos toman. Tal vez puede 
aceptar como mal menor algunos procesos revolucionarios y mantenerse frente a ellos en posición de vigilante crítica y de apoyo ponderado, pero no puede caer en fáciles simplificaciones, las cuales desconocen la relatividad y la pecabilidad insertas en las personas que conducen los procesos, y la complejidad del conjunto de los procesos sociales, la cual implica un proyecto nacional.

\section{A modo de conclusión}

La teologí de la liberación, de hecho, ha tenido y sigue teniendo un tremendo significado polltico. Así se vió en el Informe Rockefeller, en los planteamientos de Santa $\mathrm{Fe}$, en los constantes ataques a los que se ve sometida por las fuerzas conservadoras fuera y dentro de la Iglesia. Se estima que, aunque ella misma no sea por sí sola una fuerza capaz de transformar revolucionariamente la situación de América Latina, puede convertirse en un factor importante en el conjunto de fuerzas que constituyen el movimiento revolucionario. Incluso algunos de los movimientos marxistas no sólo han quitado a la fe que propugna la teología de la liberación el sambenito de ser opio del pueblo, sino que le atribuyen un papel positivo en las luchas liberadoras.

Tal reconocimiento no es infundado. La fe, la religión, y la Iglesia siguen siendo elementos especialmente significativos e influyentes en la contextura social, especialmente entre los más pobres de Latinoanérica. Si la fe y la Iglesia se ponen de lleno a favor de la causa popular, si intra y extraeclesialmente hacen efectiva la opción preferencial por los pobres y dejan de amparar conservadoramente el orden establecido, algo importante se habria conseguido. Medellín y Puebla alertaron a las fuerzas reaccionarias, las cuales midieron bien lo que podía significar para el continente un cambio tan sustancial de la Iglesia y de su predicación. Los partidarios de la seguridad nacional han llamado a ésto marxistización de la fe y marxistización de la Iglesia, porque todo cuanto entra en conflicto con los dictados de la teoría de la seguridad nacional y con las exigencias del capitalismo es tildado de marxismo. Las acusaciones no son sólo verbales. Son muchísimos los que en los últimos diez anos han sido asesinados para obligar a la Iglesia y a los más avanzados de ella -obispos, sacerdortes, laicos-a abandonar su nueva posición de denuncia y de aliento a los movimientos reivindicativos y revolucionarios. Pero ello no ha detenido el movimiento. La teología de la liberación sigue expandiéndose y consolidándose como movimiento estrictamente teológico, pero también como praxis pastoral. Por ambos flancos sigue contribuyendo al cambio social en América Latina

En dos campos sigue este avance y consolidación. El primero de ellos está dentro de la Iglesia, no sin enormes resistencias. Este campo es decisivo. Si se lograra que la Iglesia latinoamericana en cuanto tal se pusiera efectivamente en la línea de Medellín y Puebla, no sólo se lograrla una profunda transformación eclesial mucho más evangélica y evangelizadora, sino que se constituira en una fuerza muy imporante para el avance de la liberación y para que esa liberación se conformara según los valores evangélicos. El otro campo es el de poner esta 
fuerza en relación con las necesidades populares de liberación. No se ha encontrado siempre el modo de hacerlo, un modo que junte la eficacia a corto y largo plazo con el respeto a la propia mismidad cristiana y a la relativa autonomia de esa mismidad. Se trata de un problema diflcil al cual todavía no se ha dado uana respuesta para siempre. Hay todavia vacilaciones y discusiones. Sobre los puntos que han sido tralados en esta exposición hay ya mucho escrito, hay también intentos prácticos diversos, los cuales no coinciden con las líneas aqur desarrolladas. No es esta la ocasión oportuna para discutir anallicicamente otras posiciones. Con lo escrito puede bastar para plantear el problema y para situar algunas cuestiones fundamentales en la perspectiva debida. Lo importante en definitiva es salvar la plenitud del mensaje revelador y liberador de Dios en Jesucristo y de lograr su plena eficacia en la historia, en la convicción de que cuanto mejor se desarrolle el primer empeño más eficaz será el segundo; pero también en la convicción de que es necesaria la praxis, la realización histórica del reino de Dios para alcanzar teórica, vivencial y eficazmente la plenitud de ese mensaje. Las cosas se han puesto ya en marcha. Lo importante ahora es que no se ahogue el espíritu nuevo. De momento todavia hay esperanzas de que esto no va a ocurrir. 